\title{
A Linear Programming Approach to Water Allocation during a Drought
}

\author{
Jaume Freire-González ${ }^{1, *(\mathbb{D})}$, Christopher A. Decker ${ }^{2}$ and Jim W. Hall ${ }^{1}$ \\ 1 Environmental Change Institute, University of Oxford, Oxford University Centre for the Environment, \\ South Parks Road, Oxford OX1 3QY, UK; jim.hall@eci.ox.ac.uk \\ 2 Centre for Socio-Legal Studies, University of Oxford, Manor Road Building, Oxford OX1 3UQ, UK; \\ christopher.decker@csls.ox.ac.uk \\ * Correspondence: jaume.freire@ouce.ox.ac.uk
}

Received: 22 February 2018; Accepted: 21 March 2018; Published: 23 March 2018

\begin{abstract}
The economic impacts of a drought depend critically on how water is allocated to different users. Choices as to water allocation can often reflect wider economic policy, environmental, and social goals and constraints. This research applies a multi-objective linear programming input-output method to determine a suite of water supply allocations for different economic sectors in a drought. Using the UK as a case study, we develop estimates of the minimum potential economic impact associated with different water allocations under a range of climate and policy scenarios. Estimates of total impact range from $-0.16 \%$ to $-1.48 \%$ of total output depending on the drought scenarios tested. The approach offers the flexibility to set different policy objectives in terms of water allocations/ restrictions, employment or a range of other objectives, including constraints to rebalance the economic system. In allowing for the inclusion of other economic, social, and environmental constraints, it provides a framework for policymakers to assess how water allocation decisions interact with other policy goals to determine the economic impacts of a drought. Challenging decisions about how to allocate water during a drought are likely to remain important in the future.
\end{abstract}

Keywords: input-output analysis; water economics; water management; optimization

\section{Introduction}

The economic impacts of drought and water scarcity are an increasing concern for society in general, and governments specifically, in many parts of the world. Population growth, increasing urbanization, and rising incomes are all factors that are contributing to an increased risk of water scarcity and drought. These factors are amplified in many countries by the effects of changes in the climate which is seen as increasing the risk of more frequent and severe droughts, and which, in turn, can give rise to adverse environmental, social, and economic impacts. The fifth assessment report of the Intergovernmental Panel on Climate Change found - with very high confidence-that ecosystems and many human systems are vulnerable to droughts associated with recent climate-related extremes [1]. One analysis by the World Bank analysis indicates that water scarcity, exacerbated by climate change, could reduce GDP by up to $6 \%$ in some regions; lead to increased migration, and in some cases, to greater risk of conflict [2].

Drought and periods of water scarcity has become a more widespread and frequent phenomenon in Europe, and there is an expectation that this will continue if temperatures keep rising as a result of climate change [3]. The droughts experienced in Europe in 2011 and 2012 were the worst in a century and affected not only Southern and Western Europe, but also countries in Northern Europe (including the UK, France, Germany, and Poland). In the UK, a country typically associated with an abundance of water, the combination of population growth, intensifying use of water and the impacts of climate 
change is expected to result in increased water shortages and drought in some parts of the country in the future $[4,5]$. The potential for more severe and frequently occurring drought events requires that efforts be made to understand not only their potential socioeconomic impacts, but also to consider how water allocation decisions interact with other policy goals and constraints (for example, in relation to employment or the protection of certain economically and socially important industries or activities).

This paper seeks to integrate droughts into a resource allocation framework in order to simultaneously satisfy environmental and economic goals using input-output methods. The main contribution of the framework developed is that it allows for the identification of policy measures that will minimize economic impacts-by allocating water in different ways across economic sectors-in periods of drought and water scarcity. Depending on the configuration of the system, the methodology offers a wide range of policy and economic possibilities. In order to illustrate the applicability of the method, a case study is developed for the UK economy under different drought and policy scenarios.

The article is organised as follows. Section 2 contains a brief literature review of the existing studies on environmental input-output analysis and linear programming. Section 3 introduces the context of drought and water scarcity in the UK. Section 4 develops the methodology, based on linear programming and environmental input-output methods for droughts. Section 5 sets up the linear programming problem, while Section 6 assesses the economic impacts and associated with different water allocations across economic sectors, under various drought scenarios for the UK. Section 7 contains the main conclusions of the research.

\section{Previous Economic Studies}

A number of studies have applied input-output (I-O) methods to assess the economic impacts of water scarcity during a drought event [6-13]. More general reviews of empirical research on droughts include [14-17]. While these studies provide insights on economic impacts they have adopted implicit assumptions about how certain resources, in particular water, is allocated within an economy during a period of water scarcity or drought. However, the allocation of resources (water in this case) is, to some degree, within the control of some economic agents, notably regulators and water company authorities. In these circumstances it is useful to examine how different allocation decisions at the disposal of these agents interact with economic impacts, and with the achievement of other social, economic and environmental policy objectives. A useful framework to analyse these issues is provided by [18].

At the macroeconomic scale, resource allocation problems such as these have been explored through applying a linear programming approach which optimizes (maximize or minimize) some objective function related to interindustry activity given specified constraints $[19,20]$. In this sense, input-output models can be seen as special cases of linear programming problems [21,22]. Input-output analysis influenced linear programming in its early development $[20,23,24]$. This approach allows for the prioritization of different policy decisions in a general equilibrium framework, with the advantage that it seeks to optimize particular specified policy objectives/goals (including environmental objectives). For example, as described in Sections 4 and 5 below, it can allow for the modelling of water allocations across sectors of an economy, which will minimise the overall economic impact.

Environmental objectives and constraints have been incorporated within the optimization framework in several ways. An early example is [25] which combines the impact analysis version of the generalized input-output model along with the planning form and goal programming (Goal programming is an aggregating methodology for solving multi-objective programming decision aid processes [26,27]) in an integrated approach called 'policy programming' which includes environmental extensions. Recent research that has combined environment-economy objectives and constraints inside an optimization framework have looked at: solid waste management and recycling strategies [28]; carbon emissions given the potential for technological change [29]; wastewater treatment options [30]; biomass production and trade under resource and footprint constraints [31]; and energy security [32]. A number of studies have applied an optimization approach to issues in the energy sector. He et al. [33] analyse the maximum level of energy import reduction that the economy can maintain without 
reducing final domestic demand. Jayaraman et al. [34] develop a goal programming input-output model to examine the efficient allocation of resources to achieve sustainability related goals on GDP, electricity consumption and GHG emissions for the United Arab Emirates. Carvalho et al. $[35,36]$ use a similar method to assess the trade-offs between economic, energy, environmental, and social objectives in Brazil, and Hristu-Varsakelis et al. [37] apply the approach to Greece. A useful review of recent literature that couples input-output analysis with multiobjective linear programming models for the study of economy-environment trade-offs is presented in [38].

A small but growing number of studies have applied an input-output linear programming (IO-LP) approach to address the issue of water resources planning in the context of drought and water scarcity. Harris and Rea [39] and Henry and Bowen [40] apply IO-LP to the US context for the purposes of identifying water resource allocations that maximise gross regional value added/production, while allowing for specific regional policy goals/constraints, including labour. Liu et al. [41] applied an IO-LP approach to estimate water shadow prices for nine Chinese water basins. López-Morales and Duchin [42,43] applied an IO-LP approach (based on the World Trade Model, WTM) to 13 hydroeconomic regions in Mexico with the aim of minimizing factor use to satisfy final demand. López-Morales and Duchin [42] defined and quantified sustainable endowments of water under different scenarios relating to water withdrawals. Springer and Duchin [44] applied the WTM at the global level to analyse alternative scenarios about future food requirements, having regard to land use and freshwater use, while [45] extended the WTM to incorporate the potential reuse of wastewater from economic activities. This paper is similar to these studies in that it allows for choices to be made about water resource allocation against a context of multiple goals and constraints. However, our analysis is focussed on how, in the context of water scarcity and drought, reductions in water availability for different industries or economic sectors led to reductions in final demand under different pre-specified constraints.

\section{Drought and Water Scarcity in the UK}

Although drought and water scarcity are usually associated with arid and semi-arid regions (such as Africa, Australia, the Middle East, and parts of Asia and South America), countries in Europe have also experienced significant episodes of drought and water scarcity over the past three decades. Analysis by the European Commission [46] estimated that, at that time, some 11\% of Europe's population, and $17 \%$ of its territory, had been affected by water scarcity. The same analysis estimated the cost of droughts in Europe over the past thirty years at EUR 100 billion. Climate change projections suggest that the risk of periods of drought and water scarcity is likely to increase in the future as a result of warmer winters in Northern Europe and hotter summers in the South of Europe, and as a result of reduced precipitation and increasing evaporation demand.

In the UK, droughts are considered to be a headline strategic risk. The UK Government's Committee on Climate Change (CCC) has identified a risk that, even with low population growth and modest climate change, there is the potential for severe water supply deficits across the UK [5]. The CCC emphasised that this could give rise to trade-offs between the different uses of water (industry, agriculture, the public water supply, and ecological uses), which is the issue at the core of this research.

Exploring the impacts of drought and episodes of water scarcity on the UK economy is of interest for a number of reasons. First, the UK is an advanced, developed economy with high levels of urbanisation and population growth in some areas (such as London and the South East); this means that the causes and drivers of water scarcity and drought tend to be highly associated with human decisions and movements, which, to some degree, is within the realm of policy. Second, relative to other parts of the world, the UK has high levels of hydraulic capital which can be managed over the short and long-term to address issues of water scarcity. A key focus is how the available water is allocated across different competing uses over time, including economic and ecological uses, which involves different economic and distributional impacts. Third, in England, water companies are privately owned and the responsibility for water resources planning and drought management (i.e., water 
allocation during a drought) is co-managed between these private operators, independent regulators, government agencies, and other stakeholders. Finally, the structure of the UK economy is heavily skewed toward the provision of services (over $78 \%$ ) followed by relatively small manufacturing $(10 \%)$ and construction $(7 \%)$ sectors. The contribution of the agricultural sector is estimated at less than $1 \%$. This means that the impacts of water scarcity on the economy and on wider society may be more complex to examine than in more agricultural or manufacturing reliant economies, where it is easier to isolate and identify the water footprint. All of these factors mean that the drivers of future water scarcity and drought (urbanisation, population growth, intensified use of water by some activities and users, etc.), and the associated impacts, can, albeit to different degrees, potentially be shaped and managed by choices made about competing allocations of water over the short- and long-term.

\section{Linear Optimisation Approach for Droughts}

This section describes how the linear optimisation approach has been applied to assess the economic impacts and to obtain a suite of efficient water allocation policy options during a drought. The model described calculates reductions in final demand that would make the economic model feasible when there is less water available and no adoption of new technologies are allowed. The technology assumption is based on the use of a short term framework of analysis which is most relevant for drought management.

\subsection{Water Input-Output Model}

The water input-output model can be developed in a similar way to other environmental extended input-output models (EEIO). It is a straightforward way to assess the total water consumption of an economy from different consumption patterns, linking water use with interindustry relationships and final demand [47-49].

Two main sources of water for the economic system can be defined, which, for the purposes of the analysis that follows, we have labelled 'green water' and 'blue water'. 'Green water' is defined as: "the precipitation on land that does not run off or recharge the groundwater, but is stored in the soil or temporarily stays on top of the soil or vegetation. Eventually, this part of precipitation evaporates or transpires through plants. Green water can be made productive for crop growth (although not all green water can be taken up by crops, because there will always be evaporation from the soil and because not all periods of the year or areas are suitable for crop growth)". 'Blue water' can be defined as: "fresh surface and groundwater, in other words, the water in freshwater lakes, rivers and aquifers" (http://waterfootprint.org/en/water-footprint/glossary/). A drought event is a function of both climate conditions-affecting green water and part of blue water-and policy conditions-affecting blue water [18]. It is assumed that a drought event will lead to a reduction of water availability for different economic sectors, and this is the source of economic impact. Other economic impacts form droughts can also arise: changes in consumption patterns, secondary effects (such as fires, desertification, etc.), etc.

Following [19], in order to account for water use associated with interindustry activity, we have assumed a matrix of direct use coefficients of water, $D^{w}=\left[d_{k j}^{w}\right]$, each element of which is the amount of water source $k$ (green and blue water, for instance) generated per monetary unit in industry $j$ output. The level of water use associated with each activity can be expressed in matrix terms as:

$$
X^{w *}=D^{w} X
$$

where $X^{w *}$ is the vector of water use and $x$ is the total output. On the other hand, the traditional Leontief model can be expressed as:

$$
X=(I-A)^{-1} F
$$

where $(I-A)^{-1}$ is the inverse matrix of the Leontief production model [50,51], and $f$ is the final demand for economic sectors. Let's rename $(I-A)^{-1}=M$. 
Inserting Equation (2) into Equation (1), we can compute $x^{w *}$ as a function of final demand:

$$
X^{w *}=\left[D^{w} M\right] F
$$

The expression inside brackets is the matrix of total water use coefficients. The elements of this matrix represent the total water use generated per each monetary unit of final demand presented to the economy. This expression allows for the assessment of total water use in the economy-direct and indirect-after changes in final consumption patterns. This approach assumes that water use varies linearly with output.

\subsection{Generalized Input-Output Optimization Model}

The classical Leontief input-output model of impact assessment—Equation (2) above—can be rewritten in an alternative form:

$$
(I-A) X=F
$$

From this expression and Equation (1) above a system of equations can be expressed from the water use and the production side. This equation system can be expressed in arrays by concatenating Equations (1) and (4) as it follows:

$$
\left[\begin{array}{c}
D^{w} \\
(1-A)
\end{array}\right] X=\left[\begin{array}{c}
X^{w *} \\
F
\end{array}\right]
$$

This is also known as the planning form [19] of input-output analysis, in contraposition to the impact analysis form (Equations (2) and (3) above).

Other equations can also be added to the system regarding other economic or environmental conditions. Moreover, disaggregations of different water sources are also possible by breaking down $D^{w}$ and $x^{w *}$ variables.

Equation (5) represents a system of linear equations and so, can be solved as a linear programming problem. These are equations for water use:

$$
d_{1} x_{1}+d_{2} x_{2}+\cdots+d_{n} x_{n}=x^{w *}
$$

Below are the set of equations that lead to economic equilibrium within the input-output context:

$$
\begin{gathered}
\left(1-a_{11}\right) x_{1}-a_{12} x_{2}-\cdots-a_{1 n} x_{n}=f_{1} \\
-a_{21} x_{1}+\left(1-a_{22}\right) x_{2}-\cdots-a_{2 n} x_{n}=f_{2} \\
-a_{21} x_{1}-a_{22} x_{2}-\cdots+\left(1-a_{n n}\right) x_{n}=f_{n}
\end{gathered}
$$

Equation (6) is a representation of Equation (1) above, showing water use along the economy; while the set of Equation (7) is a representation of Equation (4), showing the interindustry equilibrium of the economy. Given that the total water used in the economy is reduced under a drought situation, the linear program problem can be specified as:

$$
\operatorname{Max} Z=\sum_{i=0}^{n} x_{i}
$$

subject to:

$$
\begin{gathered}
d_{1} x_{1}+d_{2} x_{2}+\cdots+d_{n} x_{n} \leq x^{w *} \\
\left(1-a_{11}\right) x_{1}-a_{12} x_{2}-\cdots-a_{1 n} x_{n} \leq f_{1} \\
-a_{21} x_{1}+\left(1-a_{22}\right) x_{2}-\cdots-a_{2 n} x_{n} \leq f_{2} \\
\cdots \cdots+ \\
-a_{21} x_{1}-a_{22} x_{2}-\cdots+\left(1-a_{n n}\right) x_{n} \leq f_{n}
\end{gathered}
$$




$$
X_{n} \geq 0
$$

The problem can be solved by finding the set of variables $X$ that maximize $Z$, subject to different constraints. The point of this system is to maximize the total output of the economy, given a water use restriction, provided by Equation (9), and an economic equilibrium restriction, given by the set of Equation (10). A non-negativity condition of sectorial outputs has been added to the system (Equation (11)). In this system of equations, variable $x^{w *}$ represents the total water use of the economic system, so it is possible to find another global equilibrium if it is reduced, as it might be expected under a drought situation. In other words, if final demand and output are free variables, there is no unique solution of the IO standard model. By adding this constraint, we try to find a solution in terms of final demand and output, satisfying each water allocation combination. Note that additional and different types of constraints can be added, depending on the definition of the system and its boundaries.

The input-output framework we use in this simple formulation does not allow for technology changes (as we use fixed input-output coefficients). While this is a weakness of the methodology, it should be balanced against the advantage that it is a simple model that allows policy-makers to easily implement it for short-term assessments (which is most relevant during a drought event). Some approaches like the Rectangular Choice of Technology model allow for a choice among technologies [43]. However, in this research we assume that technology changes are only expected in the mid- and long-run, depending on the persistence of droughts.

\section{Problem Setup}

Following the approach developed in the last section, we setup the problem of droughts as the optimisation of a linear program. We assume that a drought event implies a reduction in the availability of green water and some reduction of blue water. Green water reduction comes from the specific climate conditions. Blue water reductions come in part from climate conditions, but also from decisions about water allocation to different sectors. In times of scarcity, water allocation will inevitably involve restricting the amount of water allocated to various sectors.

The approach can also be used to obtain estimates of the blue water allocation that authorities should implement, given a global water reduction on water resources, and other environmental and economic restrictions (like climate conditions or maximum levels of water restriction per economic sector). Specifically, the approach can be applied to determine which combination of water allocations maximize total economic output, so that they are most efficient in economic terms. This optimal combination of water allocations can be determined by the linear optimisation problem:

$$
\operatorname{Max} Z=\sum_{i=0}^{n} x_{i}
$$

subject to:

$$
\begin{aligned}
& d_{i}^{w g} x_{i} \leq x_{i}^{w * g}, i=1 \ldots n \\
& \sum_{i}^{n} d_{i}^{w b} x_{i} \leq \sum_{i}^{n} x_{i}^{w * b}, i=1 \ldots n \\
& l_{i} x_{i} \leq L_{i}, i=1 \ldots n \\
& \left(1-a_{i j}\right) x_{i} \leq f_{i}, i=1 \ldots n, j=1 \ldots m \\
& x_{i} \geq 0, i=1 \ldots n
\end{aligned}
$$

$d_{i}^{w w g}$ is green water coefficient of sector $i$, and $d_{i}^{w b}$ is blue water coefficient of sector $i$. As we consider sectoral water allocations in times of scarcity, they are both a matrix of coefficients. Specifically, they represent the diagonalization of direct use coefficients of water vectors, for green water and for blue water. $x_{i}^{w * g}$ is the direct green water use of economic sector $i$ and, $x_{i}^{w * b}$ is the direct blue water use of economic sector $i$. Elements of those vectors are the ones that will change to test different scenarios. We have also added $l$ as the labour coefficients, and $L$ the total employment of the economy, so an additional restriction 
that allows a wider range of policy objectives has been introduced. This is something that can be avoided when a program like this is set up, but we have added it to show the diversity of policy objectives that can be included in this framework. Set of equations $\left(1-a_{i j}\right) x_{i} \leq f_{i}$ assume that production meets final demand, but can also be lower. This is due to the specification of the problem as the maximization of total production, and due to the assumption that reductions in final water availability for economic sectors $\left(X^{w * g}, X^{w * b}\right)$ due to a drought will constrain production. An additional constraint of non-negativity of outputs of individual economic sectors has been also added.

The specification of the problem is similar to the previous one (Equations (8)-(11)), however, a global objective is solved in relation to total blue water reduction $\left(\sum_{i}^{n} x_{i}^{z * b}\right)$. This allows the system to rebalance itself in order to obtain the maximum output level by adjusting the different sectoral blue water allocations that achieve that output. Green water sectoral use is determined by climate conditions.

So far, the stated problem has only considered economic efficiency objectives as specified (maximum possible total economic output). However, we recognise that this could lead to strange results that are undesirable or impossible to achieve in real world, such as a total reduction of water supplied to specific economic sectors. Given that input-output methods are based on economic efficiency, water is assigned to sectors that (directly and indirectly) are more efficient in the use of water, provided by the water coefficients. One potential consequence would be that, one sector, directly and indirectly intensive in the use of water could disappear in a context of water scarcity, if we only consider economic efficiency. Of course, this can be informative from the policy-making point of view, but it is not realistic considering other socio-economic conditionings of real economies. In order to avoid such results and to make the model more realistic, additional constraints can be added, for instance, regarding the minimum percentage of output reduction in each economic sector:

$$
\operatorname{Max} Z=\sum_{i=0}^{n} x_{i}
$$

subject to:

$$
\begin{aligned}
& d_{i}^{w g} x_{i} \leq x_{i}^{w * g}, i=1 \ldots n \\
& \sum_{i}^{n} d_{i}^{w b} x_{i} \leq \sum_{i}^{n} x_{i}^{w * b}, i=1 \ldots n \\
& l_{i} x_{i} \leq L_{i}, i=1 \ldots n \\
& \left(1-a_{i j}\right) x_{i} \leq f_{i}, i=1 \ldots n, j=1 \ldots m \\
& x_{i} \geq\left(1-p_{i}\right) x_{0 i}, i=1 \ldots n
\end{aligned}
$$

where $p_{i}$ is the percentage of reduction of initial output $\left(x_{0}\right)$, and $x_{i}$ is the minimum sectoral output. There are other possible ways of introducing such a constraint including: establishing minimum absolute values, applying limits to final demands, or limiting the absolute, or percentage, restrictions to blue water allocations applied to each sector, etc.

Once we have outputs of individual economic sectors, the blue water allocations for each economic sector will be determined by multiplying them by the blue water coefficients and, hence, obtaining the new water supply for each specific sector:

$$
d_{i}^{w b} x_{i} i=1 \ldots n
$$

\section{Assessment and Policy Strategies for Droughts in the UK}

\subsection{Data}

Two main datasets are necessary in order to implement the proposed framework: economic accounts in I-O table form, and water accounts homogeneous with I-O tables, which separate the direct green and blue water use of different economic sectors. The Exiobase dataset $[52,53]$ offers a 
multiregional I-O framework for 2007, including water accounts disaggregated between green water, blue water, and water withdrawals.

As we want to apply the method in a simplified way for the UK economy, without multiregional implications, we have isolated the UK I-O table and its water accounts. The UK table includes 163 sectors with a high disaggregation for agriculture. However, the problem stated also allows for the use of a multiregional framework.

To summarize, the resulting system contains a total of 815 constraint equations: 163 equations for green water; 163 for blue water; 163 for labour; 163 for production meeting final demand; and 163 that set up the constraint that each individual production has to be greater than zero.

\subsection{Scenarios}

The integrated framework is calibrated to assess economic impacts of a specific drought event under different policy options or choices. Depending on the specification of the problem and objectives, the total reduction of blue water can be determined exogenously or endogenously, however, green water is mainly derived from exogenous climate conditions.

In setting out a spectrum of scenarios our motivation here is to establish an upper and lower bound on potential impacts. This is important in the policy context of consideration of the impacts from low to extreme drought events in the UK. Hence, we first develop two scenarios of green water availability and two of blue water availability for the economic system. Green water is solely determined by climate conditions. However, blue water availability is determined by two factors: climate conditions and policy conditions/choices (the level of water restrictions on water allocation applied by authorities). We then introduce these scenarios into the optimisation framework to obtain the final output.

Table 1 shows the different climate scenarios and their potential effects on green and blue water reduction for several economic sectors. It is expected that climate conditions affect green water availability and part of blue water, specifically that part used by abstractors from river flows (mainly water suppliers, agriculture, power generators and some industries). Table 2 shows two different possibilities of water restrictions in different economic sectors applied by authorities and private agents during a drought event (part of blue water). Scenario 1 assumes a reduction of $5 \%$ for agriculture and $1 \%$ for services. In contrast, scenario 2 assumes $75 \%$ for agriculture and 30\% for services, this being the most extreme scenario. We recognise that the extreme scenario is too restrictive to be applied in reality. However, simulations from this scenario have to be interpreted as an exercise to show the upper boundaries of this approach.

Table 1. Annual average percentage reduction of green water and blue water at different climate scenarios.

\begin{tabular}{ccc}
\hline & Green Water & \\
\hline Sector & Low Severity & High Severity \\
Agriculture & $\mathbf{2 0 \%}$ & $\mathbf{8 0 \%}$ \\
\hline Sector & Blue Water & \\
\hline Agriculture & Low severity & High severity \\
Power generation & $20 \%$ & $80 \%$ \\
Water supply & $20 \%$ & $80 \%$ \\
Other recreational activities & $20 \%$ & $80 \%$ \\
\hline
\end{tabular}

Source: own elaboration. 
Table 2. Annual average percentage reduction of blue water at different policy scenarios: water supply restrictions.

\begin{tabular}{ccc}
\hline Sector & Low Restriction (1) & High Restriction (2) \\
\hline Agriculture & $5 \%$ & $75 \%$ \\
Extraction and mining & $5 \%$ & $50 \%$ \\
Manufacture & $5 \%$ & $50 \%$ \\
Power generation & $2 \%$ & $25 \%$ \\
Water supply & $2 \%$ & $25 \%$ \\
Services & $1 \%$ & $30 \%$ \\
\hline
\end{tabular}

Source: own elaboration.

In total, four scenarios have been analysed. Note that as these are only hypothetical cases, between scenario 1 and scenario 4 many other options are possible. The exact form of any reduction will be determined by climate conditions, the level and composition of hydraulic stock of capital and short-term policy decisions on water restrictions.

On the basis of these scenarios, we have allocated the 163 sectors of the I-O table for the UK economy to one of these six aggregated categories. It is assumed that these sectoral reductions in water use (which determines the allowed allocation of water) are equally applied across the UK economy (or they are on average, depending on the interpretation). None of these scenarios are likely to be fully realistic, as each economic sector has its own and differentiated needs and specific uses for water and will, therefore, be affected in different ways by climate conditions or policy decisions taken by authorities. However, the purpose is to illustrate how to apply this framework can be applied to an economy such as the UK.

Given that there are two sources of blue water reduction-climate scenarios and policy scenarios-the final blue water reductions for each economic sector is the maximum of the climate scenario and the policy scenario in each case.

We have obtained the total blue water reduction in the economy, provided by the mix of these 4 scenarios (two climate scenarios in combination with two policy scenarios). The inputs for the models derived from scenarios are shown in Table 3. Blue water in this table is an aggregation of blue water in Tables 1 and 2 (from climate and policy scenarios).

Table 3. Total water percentage reduction in each scenario.

\begin{tabular}{ccccc}
\hline Climate Scenario & \multicolumn{2}{c}{ Low Severity } & \multicolumn{2}{c}{ High Severity } \\
\hline Policy scenario & $(1)$ & $(2)$ & $(1)$ & $(2)$ \\
Green water & $20 \%$ & $20 \%$ & $80 \%$ & $80 \%$ \\
Blue water & $14.43 \%$ & $60.65 \%$ & $52.13 \%$ & $69.82 \%$ \\
\hline
\end{tabular}

Source: own elaboration from Tables 1 and 2 and water accounts from Exiobase.

Although a range of other possible global blue water final reductions could be applied in Table 3, we have used the scenarios listed, in order to show the example in Tables 1 and 2 from another perspective.

\subsection{Results and Discussion}

\subsubsection{Impact of Specific Water Restrictions (Allocations) on Economic Sectors}

The scenarios presented in Tables 1 and 2 have been tested with the linear optimisation problem shown in Equations (12) and (13), by reducing $x_{i}^{w * g}$ and $x_{i}^{w * b}$ values from business-as-usual scenario (initial water use) using the percentages provided by Tables 1 and 2, and then, running the specified optimization model 30 times, one per each scenario as a different constraint in green and blue water 
consumption. Table 4 shows the results in terms of total output change and total output variation (\%) in each scenario in relation to business-as-usual scenario.

Table 4. Economic impact of different drought and policy scenarios in the UK.

\begin{tabular}{|c|c|c|c|c|c|c|c|}
\hline & & \multicolumn{4}{|c|}{ Climate Scenarios } & \multirow{2}{*}{\multicolumn{2}{|c|}{ Average Values }} \\
\hline & & \multicolumn{2}{|c|}{ Low Severity } & \multicolumn{2}{|c|}{ High Severity } & & \\
\hline & & $\begin{array}{l}\text { Output Change } \\
\text { (Million } € \text { ) }\end{array}$ & $\begin{array}{c}\text { Output } \\
\text { Change (\%) }\end{array}$ & $\begin{array}{c}\text { Total Output } \\
\text { (Million } € \text { ) }\end{array}$ & $\begin{array}{c}\text { Output } \\
\text { Change (\%) }\end{array}$ & $\begin{array}{l}\text { Total Output } \\
\text { (Million } €)\end{array}$ & $\begin{array}{c}\text { Output } \\
\text { Change (\%) }\end{array}$ \\
\hline $\begin{array}{c}\text { Policy } \\
\text { scenarios }\end{array}$ & $\begin{array}{l}\text { Low } \\
\text { restriction }\end{array}$ & $-64,084.6$ & -1.73 & $-111,980.5$ & -3.02 & $-87,934.3$ & -2.37 \\
\hline \multicolumn{2}{|c|}{ Average values } & $-323,626.2$ & -8.74 & $-394,927.3$ & -10.66 & & \\
\hline
\end{tabular}

Source: own elaboration.

The results in Table 4 are annual estimates, as the scenarios are also considered annual averages. The impacts obtained range from $-1.73 \%$ of the output, assuming low restrictions and low severity of climate scenarios to $-17.13 \%$ under high restriction levels and high severity of climate conditions. Average values range from $-2.37 \%$ to $-16.68 \%$ of the output if we focus on policy scenarios, and from $-8.74 \%$ to $-10.66 \%$ if we focus on climate scenarios analysis. The individual impacts on different economic sectors will depend on the direct impact, but also on the indirect impact determined by the interrelations between economic sectors.

While high at the extreme end of the scenarios, these results are broadly consistent with the estimates of the economic impact of droughts in other studies. Several studies have found values located close to the lower bound of our results. Islam [54] estimated a $-2.4 \%$ production loss based on a green water drought which is similar to our low restriction policy scenario. Horridge et al. [55] model the impacts of a green water drought in Australia and obtains an estimate of $-1.6 \%$ GDP reduction. Studies which incorporate blue water restrictions suggest a wider gap, such as [10] which estimated a reduction of GDP in Catalonia of up to $-2.8 \%$. This study used water-GVA elasticities (less than 1) which represent the percentage change in GVA form a percentage change in water use. Nevertheless, the economic impacts in these studies are generally lower than those we estimate here. This can be attributed to a number of factors. First, most studies focus only on green-water drought impacts, and do not estimate the impacts of blue-water droughts. Second, we have assumed linear and proportional water-gross value added (GVA) coefficients, rather than using different implicit water-GVA elasticities [10]. Third, as noted, the extreme scenario modelled is too restrictive to ever be applied in reality (see Table 2). However, in presenting the results of the simulations of this extreme scenario our intention is to show the upper boundaries of this modelling approach.

Finally, although policy scenarios are expected to influence results more than climate scenarios in the assumed scenarios, it is necessary to be aware that climate conditions would affect medium and long-term policy decisions in managing blue water resources, so this is a static short-term analysis.

\subsubsection{Water Allocations for Economic Sectors in the UK}

The linear programming problem in Equations (14) and (15) has been tested with the global blue water reduction scenarios shown in Table 3, in order to estimate the sectoral water allocations that maximize the total output of the economy while minimising the economic impact of a drought (Table 5).

The total output reductions in Table 5 are associated with a specific allocation of water to different economic sectors. These have been obtained by applying Equation (16). The results in Table 5 show the minimum impact in total output of the UK economy under different scenarios of the total water reduction (as shown in Table 3). For instance, if we analyse the most extreme scenario, both in climate and policy terms, we could theoretically assume a reduction of green water of $80 \%$ (for extreme climate 
conditions) and a blue water reduction of $69.82 \%$, and this is estimated to result in a loss of $1.48 \%$ of total economic output. However, these results are impractical in reality as it implies a total reduction of water supply for some sectors (those with relatively high water use, but whose production has a low influence on total direct and indirect economic impact) combined with low restrictions being applied to sectors that have the most significant macroeconomic impact. This is because the results have been generated, considering only economic efficiency and not having regard to equity, social, and other factors.

Table 5. Minimum potential economic impact of different climate and policy scenarios in the UK.

\begin{tabular}{|c|c|c|c|c|c|c|c|}
\hline & & \multicolumn{4}{|c|}{ Climate Scenarios } & \multicolumn{2}{|c|}{ Average Values } \\
\hline & & $\begin{array}{l}\text { Output Change } \\
\text { (Million } € \text { ) }\end{array}$ & $\begin{array}{c}\text { Output } \\
\text { Change }(\%)\end{array}$ & $\begin{array}{l}\text { Total Output } \\
\text { (Million } € \text { ) }\end{array}$ & $\begin{array}{c}\text { Output } \\
\text { Change }(\%)\end{array}$ & $\begin{array}{l}\text { Total Output } \\
\text { (Million } € \text { ) }\end{array}$ & $\begin{array}{c}\text { Output } \\
\text { Change (\%) }\end{array}$ \\
\hline \multirow{2}{*}{$\begin{array}{c}\text { Policy } \\
\text { scenarios }\end{array}$} & $\begin{array}{c}\text { Low } \\
\text { restriction }\end{array}$ & $-5,977.1$ & $-0.16 \%$ & $-23,137.8$ & $-0.62 \%$ & $-14,486.9$ & $-0.39 \%$ \\
\hline & $\begin{array}{l}\text { High } \\
\text { restriction }\end{array}$ & $-27,579.7$ & $-0.74 \%$ & $-54,743.8$ & $-1.48 \%$ & $-37,754.1$ & $-1.02 \%$ \\
\hline \multicolumn{2}{|c|}{ Average values } & $-14,580.5$ & $-0.39 \%$ & $-35,888.7$ & $-0.97 \%$ & & \\
\hline
\end{tabular}

Source: own elaboration.

Additional constraints can be added to obtain results that allow for certain policy and social requirements. This, however, requires that we accept a greater total impact on macroeconomic output than shown in Table 5. Given that in reality, the results shown in Table 5 are undesirable as many sectors will see their water allocation reduced to zero, we have tested the linear optimisation problem shown at Equations (14) and (15), but added additional constraints in terms of the maximum output reduction in each economic sector.

Table 6 shows the same optimization problem with an additional constraint of applying a maximum reduction of total output in all economic sectors of $90 \%$. It is also possible to apply specific maximum reductions for each economic sector depending on the needs, but for illustrative purposes maximums have been applied to all sectors, and in order to simplify conclusions.

Table 6. Minimum potential economic impact of different climate and policy scenarios in the UK with the additional constraint of a maximum output reduction of $90 \%$ in each economic sector.

\begin{tabular}{|c|c|c|c|c|c|c|c|}
\hline & & \multicolumn{4}{|c|}{ Climate Scenarios } & \multirow{2}{*}{\multicolumn{2}{|c|}{ Average Values }} \\
\hline & & \multicolumn{2}{|c|}{ Low Severity } & \multicolumn{2}{|c|}{ High Severity } & & \\
\hline & & $\begin{array}{l}\text { Output Change } \\
\text { (Million } € \text { ) }\end{array}$ & $\begin{array}{c}\text { Output } \\
\text { Change (\%) }\end{array}$ & $\begin{array}{l}\text { Total Output } \\
\text { (Million } € \text { ) }\end{array}$ & $\begin{array}{c}\text { Output } \\
\text { Change (\%) }\end{array}$ & $\begin{array}{c}\text { Total Output } \\
\text { (Million } € \text { ) }\end{array}$ & $\begin{array}{c}\text { Output } \\
\text { Change (\%) }\end{array}$ \\
\hline \multirow{2}{*}{$\begin{array}{l}\text { Policy } \\
\text { scenarios }\end{array}$} & $\begin{array}{l}\text { Low } \\
\text { restriction }\end{array}$ & -5980.0 & $-0.16 \%$ & $-25,761.2$ & $-0.70 \%$ & $-15,373.0$ & $-0.42 \%$ \\
\hline & $\begin{array}{l}\text { High } \\
\text { restriction }\end{array}$ & $-39,138.7$ & $-1.06 \%$ & $-99,877.0$ & $-2.70 \%$ & $-61,250.7$ & $-1.66 \%$ \\
\hline \multicolumn{2}{|c|}{ Average values } & $-18,476.7$ & $-0.50 \%$ & $-54,751.9$ & $-1.48 \%$ & & \\
\hline
\end{tabular}

The total output reductions in Table 6 are associated with a specific allocation of water across different economic sectors. These have been obtained by applying Equation (16). As expected, the economic losses are higher in Table 6 than in Table 5 as we apply the more realistic assumption that the maximum total output reduction for each sector is $90 \%$. This means that we allow for some production in all economic sectors, but this comes at the cost of increased losses in total output. Although we have been able to estimate a feasible solution applying this constraint, it should be noted that is not always possible to obtain such results. If for instance we reduce total output to some minimum point, or we add additional restrictions, it might not be possible to find a solution. 


\section{Conclusions}

Against the background of increasing policy concern about the economic impacts of drought and water scarcity, this research applies an IO-LP approach to illustrate how choices made about water allocation can minimise economic production losses at both the aggregate and sectoral level. Our aim is to set out a simple framework that could be applied to determine a set of water allocations for different economic sectors in a drought or water scarcity event. The approach offers the flexibility to set different policy objectives in terms of water allocations/restrictions, employment or a range of other objectives, including constraints to rebalance the economic system.

To illustrate how the approach can be applied, we analysed several different climate and policy management scenarios for the UK economy. Although, in practice, it is unlikely that a simple approach based on minimising total economic losses would be used to determine water allocations across different economic sectors-as they would likely involve extreme reductions for specific sectors-the framework developed allows for additional, and more realistic, constraints to be introduced to refine the analysis (such as imposing a maximum total output restriction for each sector).

Long-term policy planning of water resources can, to some degree, mitigate the need to have to make difficult water supply allocation decisions during a drought by having sufficient blue water reserves within the system. Moreover, green water droughts could also be partially avoided with good planning of resources and a good and flexible hydraulic stock of capital. However, the development, operation and maintenance of this stock involves private, environmental, and social costs, and these costs may not be efficient after a certain tolerance level. As a consequence, challenging decisions about how to allocate water during a drought are likely to remain important in the future.

Acknowledgments: This research is part of a NERC funded project: MaRIUS project: Managing the Risks, Impacts and Uncertainties of droughts and water Scarcity (NE/L010364/1).

Author Contributions: J.F.-G. developed the idea, found the data, built and ran the models, and wrote part of the paper. C.A.D. provided ideas and wrote part of the paper. J.W.H. provided ideas and reviewed the paper.

Conflicts of Interest: The authors declare no conflict of interest.

\section{References}

1. Intergovernmental Panel on Climate Change. Climate Change 2014: Impacts, Adaptation and Vulnerability: Top level findings from the Working Group II AR5, Summary for Policy Makers; Intergovernmental Panel on Climate Change: Geneva, Switzerland, 2015.

2. World Bank. High and Dry: Climate Change, Water, and the Economy; World Bank: Washington, DC, USA, 2016.

3. European Commission. Report on the Review of the European Water Scarcity and Droughts Policy; European Commission: Brussels, Belgium, 2012.

4. Cave, M. Independent Review of Competition and Innovation in Water Markets: Final Report; DEFRA: London, UK, 2009.

5. Committee on Climate Change. UK Climate Change Risk Assessment 2017 Synthesis Report: Priorities for the Next Five Years; Committee on Climate Change: London, UK, 2016.

6. Kulshreshtha, S.N.; Grant, C.W.; Marleau, R.; Guenther, E. Technical Report: Canadian Droughts of 2001 and 2002; Saskatchewan Research Council: Saskatoon, SK, Canada, 2003.

7. Howitt, R.; Medellín-Azuara, J.; MacEwan, D.; Lund, J.; Sumner, D. Economic Analysis of the 2014 Drought for California Agriculture Center for Watershed Sciences; University of California: Davis, CA, USA, 2014.

8. González, F.; Ventosa, J.P. Consum d'aigua i anàlisi input-output: Simulació de l'impacte macroeconòmic de restriccions sectorials en l'abastament d'aigua. Nota D'economia 2009, 93, 107-126.

9. Pérez, P.Y.; Barreiro-Hurlé, L. Assessing the socioeconomic impacts of drought in the Ebro River Basin. Span. J. Agric. Res. 2009, 7, 269-280.

10. Freire-González, J. Assessing the Macroeconomic Impact of Water Supply Restrictions through an InputOutput Analysis. Water Resour. Manag. 2011, 25, 2335-2347. [CrossRef]

11. Jenkins, K. Indirect economic losses of drought under future projections of climate change: A case study for Spain. Nat. Hazard. 2013, 69, 1967-1986. [CrossRef] 
12. Pagsuyoin, S.A.; Santos, J.R. Modeling the effects of drought in urban economies using input-output analysis. Br. J. Environ. Clim. Chang. 2014, 5, 134-146. [CrossRef]

13. Freire-González, J.; Decker, C.; Hall, J.W. A scenario-based framework for assessing the economic impacts of potential droughts. Water Econ. Policy 2017, 3, 1750007. [CrossRef]

14. Ding, Y.; Hayes, M.J.; Widhalm, M. Measuring Economic Impacts of Drought: A Review and Discussion. Nat. Resour. 2010, 20, 434-446. [CrossRef]

15. Logar, I.; van den Bergh, J. Methods to Assess Costs of Drought Damages and Policies for Drought Mitigation and Adaptation: Review and Recommendations. Water Resour. Manag. 2013, 27, 1707-1720.

16. Meyer, V.; Becker, N.; Markantonis, V.; Schwarze, R.; van den Bergh, J.C.J.M.; Bouwer, L.M.; Bubeck, P.; Ciavola, P.; Genovese, E.; et al. Review article: Assessing the costs of natural hazards-State of the art and knowledge gaps. Nat. Hazards Earth Syst. Sci. 2013, 13, 1351-1373.

17. Young, R.A.; Loomis, J.B. Determining the Economic Value of Water: Concepts and Methods; Routledge: New York, NY, USA, 2014.

18. Freire-González, J.; Decker, C.; Hall, J.W. The economic impacts of droughts: A framework for analysis. Ecol. Econ. 2017, 132, 196-204. [CrossRef]

19. Miller, R.E.; Blair, P.D. Input-Output Analysis: Foundations and Extensions, 2nd ed.; Cambridge University Press: Cambridge, UK, 2009.

20. Vogstad, K.O. Input-output analysis and linear programming. In Handbook of Input-Output Economics in Industrial Ecology; Eco-Efficiency in Industry and Science; Suh, S., Ed.; Springer: New York, NY, USA, 2009; pp. 801-818.

21. Dorfman, R.; Samuelson, P.; Solow, R. Linear Programming and Economic Analysis; McGraw-Hill: New York, NY, USA, 1958.

22. Intriligator, M. Mathematical Optimization and Economic Theory; Prentice-Hall: Englewood Cliffs, NJ, USA, 1971.

23. Dantzig, G. Linear Programming and Extensions; Princeton University Press: Princeton, NJ, USA, 1963.

24. Albers, D.; Reid, C. An interview with George B. Dantzig: The father of linear programming. Coll. Math. J. 1986, 17, 292-314.

25. Blair, P. Multiobjective Regional Energy Planning; Martinus Nijhoff Publishers: Leiden, The Netherlands, 1979.

26. Charnes, A.; Cooper, W.W. Chance constraints and normal deviates. J. Am. Stat. Assoc. 1952, 57, $134-148$.

27. Charnes, A.; Cooper, W.W.; Ferguson, R. Optimal estimation of executive compensation by linear programming. Manag. Sci. 1955, 1, 138-151.

28. Kondo, Y.; Nakamura, S. Waste input-output linear programming model with its application to eco-efficiency analysis. Econ. Syst. Res. 2005, 17, 393-408.

29. Wilting, H.C.; Faber, A.; Idenburg, A.M. Investigating new technologies in a scenario context: Description and application of an input-output method. J. Clean. Prod. 2008, 16, S102-S112. [CrossRef]

30. Lin, C. Identifying lowest-emission choices and environmental pareto frontiers for wastewater treatment wastewater treatment input-output model based linear programming. J. Ind. Ecol. 2011, 15, 367-380. [CrossRef]

31. Tan, R.R.; Aviso, K.B.; Barilea, I.U.; Culaba, A.B.; Cruz, J.B., Jr. A fuzzy multi-regional input-output optimization model for biomass production and trade under resource and footprint constraints. Appl. Energy 2012, 90, 154-160. [CrossRef]

32. Dilekli, N.; Duchin, F. Prospects for Cellulosic Biofuel Production in the Northeastern United States. J. Ind. Ecol. 2015, 20, 120-131.

33. He, P.; Ng, T.S.; Su, B. Energy import resilience with input-output linear programming models. Energy Econ. 2015, 50, 215-226.

34. Jayaraman, R.; Colapinto, C.; La Torre, D.; Malik, T. Multi-criteria model for sustainable development using goal programming applied to the United Arab Emirates. Energy Policy 2015, 87, 447-454. [CrossRef]

35. Carvalho, A.L.; Antunes, C.H.; Freire, F.; Henriques, C.O. A hybrid input-output multi-objective model to assess economic-energy-environment trade-offs in Brazil. Energy 2015, 82, 769-785.

36. Carvalho, A.L.; Antunes, C.H.; Freire, F.; Henriques, C.O. A multi-objective interactive approach to assess economic-energy-environment trade-offs in Brazil. Renew. Sust. Energy Rev. 2016, 54, 1429-1442. [CrossRef]

37. Hristu-Varsakelis, D.; Karagianni, S.; Pempetzoglou, M.; Sfetsos, A. Optimizing production with energy and GHG emission constraints in Greece: An input-output analysis. Energy Policy 2010, 38, 1566-1577. [CrossRef] 
38. Oliveira, C.; Coelho, D.; Antunes, C.H. Coupling input-output analysis with multiobjective linear programming models for the study of economy-energy-environment-social (E3S) trade-offs: A review. Ann. Oper. Res. 2014. [CrossRef]

39. Harris, T.R.; Rea, M.L. Estimating the value of water among regional sectors using the 1972 National Interindustry Format. Water Resour. Bull. 1984, 20, 193-201. [CrossRef]

40. Henry, M.S.; Bowen, E. A method for estimating the value of water among sectors of a regional economy. South. J. Agric. Econ. 1981, 13, 125-132. [CrossRef]

41. Liu, X.; Chen, X.; Wang, S. Evaluating and Predicting Shadow Prices of Water Resources in China and its Nine Major River Basins. Water Resour. Manag. 2009, 23, 1467-1478. [CrossRef]

42. López-Morales, C.; Duchin, F. Policies and Technologies for a Sustainable Use of Water in Mexico: A Scenario Analysis. Econ. Syst. Res. 2011, 23, 387-407. [CrossRef]

43. López-Morales, C.; Duchin, F. Economic Implications of Policy Restrictions on Water Withdrawals from Surface and Underground Sources. Econ. Syst. Res. 2015, 27, 154-171. [CrossRef]

44. Springer, N.P.; Duchin, F. Feeding nine billion people sustainably: Conserving land and water through shifting diets and changes in technology. Environ. Sci. Technol. 2014, 48, 4444-4451. [CrossRef] [PubMed]

45. Cazcarro, I.; López-Morales, C.; Duchin, F. The global economic costs of the need to treat polluted water. Econ. Syst. Res. 2016, 28, 295-314. [CrossRef]

46. European Commission. Communication from the Commission to the European Parliament and the Council on addressing the Challenge of Water Scarcity and Droughts in the European Union; European Commission: Brussels, Belgium, 2007.

47. Duarte, R.; Sánchez-Chóliz, J.; Bielsa, J. Water use in the Spanish economy: An input-output approach. Ecol. Econ. 2002, 43, 71-85. [CrossRef]

48. Velázquez, E. An input-output model of water consumption: Analysing intersectoral water relationships in Andalusia. Ecol. Econ. 2006, 56, 226-240. [CrossRef]

49. Hoekstra, A.Y.; Chapagain, A.K. Globalization of Water: Sharing the Planet's Freshwater Resources; Blackwell: Oxford, UK, 2008.

50. Leontief, W. Quantitative Input-output relations in the economic system of the United States. Rev. Econ. Stat. 1936, 18, 105-125. [CrossRef]

51. Leontief, W. The Structure of American Economy 1919-1939; University of Oxford: New York, NY, USA, 1941.

52. Tukker, A.; De Koning, A.; Wood, R.; Hawkins, T.; Lutter, S.; Acosta, J.; Rueda Cantuche, J.M.; Bouwmeester, M.; Oosterhaven, J.; Drosdowski, T.; et al. EXIOPOL: Development and illustrative analyses of a detailed global MR EE SUT/IOT. Econ. Syst. Res. 2013, 25, 50-70. [CrossRef]

53. Wood, R.; Stadler, K.; Bulavskaya, T.; Lutter, S.; Giljum, S.; de Koning, A.; Kuenen, J.; Schütz, H.; Acosta-Fernández, J.; Usubiaga, A.; et al. Global sustainability accounting: Developing Exiobase for multi-regional footprint analysis. Sustainability 2015, 7, 138-163.

54. Islam, N. What does a dry season mean to the Western Australian economy? A CGE investigation. Presented at the 47th Annual Conference of the Australian Agricultural and Resource Economics Society, Fremantle, Australia, 11-14 February 2003.

55. Horridge, M.; Madden, J.; Wittwer, G. The impact of the 2002-2003 drought on Australia. J. Policy Model. 2005, 27, 285-308. [CrossRef]

(C) 2018 by the authors. Licensee MDPI, Basel, Switzerland. This article is an open access article distributed under the terms and conditions of the Creative Commons Attribution (CC BY) license (http://creativecommons.org/licenses/by/4.0/). 